\title{
INTERIORIZAÇÃO DOS CURSOS DE PSICOLOGIA NO BRASIL: DESAFIOS ATUAIS À FORMAÇÃO
}

INTERIORIZATION OF PSYCHOLOGY COURSES IN BRAZIL: CHALLENGES TO TRAINING

INTERIORIZACIÓN DE LOS CURSOS DE PSICOLOGÍA EN BRASIL: DESAFÍOS ACTUALES A LA FORMACIÓN

\author{
João Paulo Macedo* \\ Carlivane de Jesus Souza* \\ Magda Dimenstein ${ }^{* * *}$ \\ Candida Dantas ${ }^{* * *}$
}

\begin{abstract}
RESUMO
Objetiva-se analisar os projetos pedagógicos dos cursos de Psicologia (PPC) localizados em cidades de médio, médio-pequeno e pequeno porte, considerando o contexto de expansão e interiorização da formação na última década. Trata-se de um estudo documental, a partir da análise de 20 PPC, com base nos seguintes eixos: perfil e localização dos cursos, caracterização geral dos PPC, ênfases curriculares/disciplinas e campo das práticas. Os cursos estão distribuídos em, pelo menos, 12 Estados brasileiros, sendo 30\% em municípios de médio porte, $45 \%$ em municípios de médio-pequeno porte e $25 \%$ em localidades de pequeno porte. São cursos mais próximos dos contextos rurais, entendidos como um espaço singular, permeados por uma multiplicidade de formas e uma diversidade de relaçóes com o mundo urbano, o que exige maior sensibilidade para apreender a complexidade e a heterogeneidade que marca os meios e os povos rurais no Brasil.

Palavras-chave: Formação em Psicologia. Ensino superior. Ambientes rurais. Projeto político-pedagógico.
\end{abstract}

\footnotetext{
Texto recebido em 25 de abril de 2017 e aprovado para publicação em 25 de setembro de 2018.

Doutor em Psicologia pela Universidade Federal do Rio Grande do Norte (UFRN) e docente no Programa de Pós-Graduação em Psicologia da Universidade Federal do Delta do Parnaíba (UFDPar) e da Universidade Federal do Ceará (UFC). E-mail: jpmacedo@ufpi.edu.br

"Psicóloga pela Universidade Federal do Piauí (UFPI). E-mail: carlivane.sj@hotmail.com

*** Doutora em Ciências da Saúde pela Universidade Federal do Rio de Janeiro (UFRJ) e docente no Programa de Pós-Graduação em Psicologia da UFRN. E-mail: mgdimenstein@gmail.com

${ }^{* * * *}$ Doutora em Psicologia pela UFRN e docente no Programa de Pós-Graduação em Psicologia da UFRN. E-mail: candida. dantas@gmail.com

Endereço: UFDPar - Campus Ministro Reis Velloso. Avenida São Sebastiāo, 2819 - São Benedito, Parnaíba-PI, Brasil. CEP: 64202-020.
} 


\section{ABSTRACT}

The aim of this study is to analyze the Pedagogical Projects of the Psychology Courses (PPC) in cities of a medium, small to medium, and small size located in the country, considering the context of expansion and interiorization of formation in the last decade. This was a document study, based on the analysis of 20 PPC, based on the following axes: profile and location of courses, general characterization of the PPC, curriculum/ modules emphasis, and practice fields. The courses are distributed in at least 12 Brazilian States, $30 \%$ being in medium-size cities, $45 \%$ in medium to small size cities, and $25 \%$ in small size cities. The courses are closer to rural contexts, as a singular space through a multiplicity of forms of diversity with the urban world, which demands major sensitivity to answer to the complexity and heterogeneity that is typical of the rural environment and its population in Brazil.

Keywords: Training in Psychology. Higher education. Rural environments. Political pedagogical projects.

\section{RESUMEN}

Se objetiva analizar los Proyectos Pedagógicos de los Cursos de Psicología (PPC) de ciudades medianas, medianas-pequeñas, y pequeñas del país, tomando en cuenta el contexto de expansión e internalización de la formación en la última década. Se trata de un estudio documental que parte del análisis de 20 PPC y está basado en los siguientes ejes: perfil y ubicación de los cursos, caracterización general de los PPC, énfasis curriculares/asignaturas y campo de las prácticas. Los cursos investigados están distribuidos en al menos 12 estados brasileños, siendo 30\% en ciudades medianas, $45 \%$ en medianas-pequeñas y $25 \%$ en pequeñas. Son cursos más cercanos a los contextos rurales, comprendidos como un espacio singular, impregnados por una multiplicidad de formas y una diversidad de relaciones con el mundo urbano, lo que requiere una mayor sensibilidad para captar la complejidad y heterogeneidad que marca los medios y la población rural de Brasil.

Palabras clave: Formación en Psicología. Educación superior. Ambiente rural. Proyecto político pedagógico.

\section{INTRODUÇÃO}

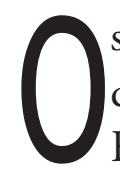

$s$ cursos de Psicologia no Brasil têm apresentado índices surpreendentes de crescimento. Em 1985, havia 81 cursos distribuídos em 17 Estados da Federação. Dez anos depois, o número de cursos quase dobrou, saltando para 149 , distribuídos nas capitais $(\mathrm{n}=75)$ e no interior $(\mathrm{n}=74)$ (Ministério da 
Educação, 1995). Em 2003, chegou-se ao número de 238 cursos de Psicologia, porém com outra distribuição entre os cursos localizados nas capitais $(\mathrm{n}=101)$ e no interior ( $\mathrm{n}=137$ ) (Ministério da Educação, 2003). Após a implantação dos programas e ações que reorientaram as políticas de ensino superior no Brasil, no período dos governos Lula-Dilma, alcançou-se em 2016 o total de 629 cursos de Psicologia, sendo 626 ativos e 3 em extinção (Ministério da Educação, 2016).

É importante ressaltar que essa reorientação das políticas de ensino superior resultou, por um lado, na expansão e interiorização da rede pública de ensino, especialmente por meio do Programa de Apoio ao Plano de Reestruturação e Expansão das Universidades Federais (Reuni), mas também representou o fortalecimento da rede privada de ensino, com o Fundo de Financiamento Estudantil (Fies) e o Programa Universidade para Todos (Prouni), consolidando a lógica privatista e neoliberal, iniciada nos governos anteriores, e aprofundando a hegemonia do setor privado na oferta de serviços educacionais no país (Macedo, Lima, Dantas, \& Dimenstein, 2017; Mancebo, Silva Júnior, \& Schugurensky, 2016).

Assim, entre os 626 cursos ativos, 80 funcionam em instituições de ensino superior (IES) públicas $(12,8 \%)$ - federais $(\mathrm{n}=54)$, estaduais $(\mathrm{n}=18)$ e municipais $(\mathrm{n}=8)$ - e 528 no setor privado $(84,3 \%)$. Ainda há 18 cursos $(2,9 \%)$ funcionando em instituições educacionais consideradas especiais. ${ }^{1}$ Tais cursos estão localizados basicamente nos Estados de Santa Catarina ( $\mathrm{n}=9)$, São Paulo $(n=6)$, Goiás $(n=2)$ e Pernambuco $(n=1)$. Especificamente no setor privado, os cursos são ofertados em faculdades isoladas $(\mathrm{n}=273)$, seguido das universidades $(\mathrm{n}=168)$ e centros universitários $(\mathrm{n}=87)$. Quanto ao número de vagas ofertadas, somente em 2016, totalizaram 106.513 em todo o País, sendo 6,37\% em IES públicas e 93,62\% em IES privadas (Ministério da Educação, 2016), dado que indica a supremacia do setor privado na educação superior no Brasil, conforme exposto anteriormente.

O panorama descrito acima indica o quanto o processo de expansão do ensino superior no Brasil vem redimensionando a formação em Psicologia nos últimos anos, especialmente por promover um maior deslocamento dos cursos de graduação dos grandes centros urbanos e capitais $(n=210,33,54 \%)$ para localidades do interior $(\mathrm{n}=416,66,46 \%)$ (Ministério da Educação, 2016). Dos 416 cursos em funcionamento em localidades do interior no ano de 2016 (52 em IES públicas, 346 em IES privadas e 18 especiais), 48 estão situados nos municípios de pequeno porte (até 49.999 hab.), 78 em médio-pequeno porte (50 mil a 99.999 hab.), 156 em médio porte (100 mil a 299.999 hab.), 78 em médio grande porte (300 mil a 499.999 hab.) e 56 em grande porte (maior que 500 mil hab.). 
Esses dados apontam, em primeiro lugar, para uma maior diversificação quanto à distribuição e localização dos cursos de Psicologia no País. Sugerem também uma ampliação no acesso e maior variedade quanto ao perfil dos estudantes que têm ingressado no ensino superior. Ademais, indicam uma aproximação dos cursos a realidades que podem constituir novos cenários de práticas, problematizações e intervençôes para profissão. Por fim, e não menos importante, despertam inúmeras interrogações acerca do processo de interiorização dos cursos de Psicologia no Brasil, considerando que a maior parte dos cursos está localizada em municípios de pequeno e médio portes, nas diversas regiôes. Portanto se trata de um quadro absolutamente distinto do que historicamente marcou nossa ciência e profissão como eminentemente urbana, voltada para o entendimento dos processos de subjetivação, modos de vida e comportamentos associados fundamentalmente a esse cenário (Leite, Macedo, Dimenstein, \& Dantas, 2013; Rosas, Rosas e Xavier, 1988).

Desse modo, indagamos sobre os atuais desafios para a formação advindos do processo de expansão e interiorização dos cursos de Psicologia. Defendemos uma perspectiva de formação ancorada em um projeto ético-político da profissão que promova não só o fortalecimento das áreas já consolidadas no campo da Psicologia, mas também responda às demandas dos novos cenários de práticas, em especial do campo das políticas públicas, direitos humanos e movimentos sociais, que marcam a realidade dos municípios de pequeno e médio porte. Nesse caminho, caberia às instituiçóes acadêmicas o desafio de criar estratégias para a formação de profissionais dotados de maior capacidade técnica e compromisso ético-político para acolher e interferir, de forma participativa, interventiva e emancipatória, nas problemáticas que se apresentam nesses cenários, valorizando a heterogeneidade espacial, social e simbólica que os permeiam. Enfrentar tais desafios é fundamental, especialmente, com o momento que se avizinha com as adequações que os cursos deverão realizar a partir da aprovação da revisão das diretrizes curriculares nacionais para os cursos de graduação em Psicologia, ocorrida em 2019 (Conselho Nacional de Educação, 2019).

Nesse trabalho, focamos na análise do perfil curricular dos cursos em funcionamento em localidades de médio, médio-pequeno e pequeno porte do Brasil, destacando a localização, a caracterização geral dos projetos pedagógicos dos cursos de Psicologia (PPC), as ênfases curriculares/disciplinas e o campo das práticas oferecido pelos cursos. Essas informações podem ajudar a traçar um panorama acerca do funcionamento dos cursos de Psicologia em localidades do interior, além de ajudar a conhecer em que medida tais cursos estão articulados às realidades e características de suas regiōes, contribuindo para repensar os rumos da formação em Psicologia no País. 


\section{METODOLOGIA}

Trata-se de uma investigação descritivo-exploratória, de base documental, baseada na análise dos projetos pedagógicos dos cursos de Psicologia (PPC) em funcionamento nos municípios de médio e pequeno porte no Brasil. Inicialmente, acessamos os microdados do Censo do Ensino Superior 2016 (Ministério da Educação, 2016), complementados com as informações da Plataforma E-MEC para dispormos dos endereços eletrônicos das IES com curso de Psicologia no Brasil. Apesar de ser obrigatório a disponibilização do PPC em seus sítios eletrônicos, a busca realizada ou o contato direto, por e-mail, dos pesquisadores com o responsável de cada curso, solicitando o documento, retornou apenas 54 PPC. Destes, 20 eram cursos oferecidos em localidades interioranas do País, sendo 5 em municípios de pequeno porte populacional, 9 de médio-pequeno porte populacional e 6 de médio porte populacional.

Os documentos foram analisados conforme modelo de análise de PPC apresentado por Seixas, Coelho-Lima, Silva e Yamamoto (2013), com base em quatro grandes eixos: perfil e localização dos cursos investigados, caracterização geral dos PPC, ênfases curriculares/disciplinas e o campo das práticas oferecidas pelos cursos. Por fim, sobre os aspectos éticos, mesmo se tratando de documentos disponíveis em domínio público, considerou-se o anonimato dos cursos na apresentação das informações.

\section{RESULTADOS}

\subsection{PERFIL E LOCALIZAÇÃO DOS CURSOS}

Tabela 1 - Perfil dos cursos em relação à organização acadêmica, natureza jurídica, ano de início, turno e quantidade de vagas

\begin{tabular}{lcc}
\hline \multicolumn{1}{c}{ Características } & N & $\%$ \\
\hline Organização acadêmica & 14 & $70,0 \%$ \\
Universidade & 3 & $15,0 \%$ \\
Centro Universitário & 3 & $15,0 \%$ \\
Faculdade & & \\
Natureza Jurídica & 8 & $40,0 \%$ \\
Público & 12 & $60,0 \%$ \\
Privado & & \\
Ano de início & 2 & $10,0 \%$ \\
1970 - 1990 & &
\end{tabular}




$\begin{array}{lcc}\text { 1991 - } 2000 & 3 & 15,0 \% \\ 2001 \text { - dias atuais } & 15 & 75,0 \% \\ \text { Turno } & 1 & 5,0 \% \\ \text { Matutino } & 12 & 60,0 \% \\ \text { Integral } & 5 & 25,0 \% \\ \text { Noturno } & 2 & 10,0 \% \\ \text { Não informado } & & \\ \text { Quantidade de vagas } & 10 & 50,0 \% \\ \text { Entre } 30 \text { e } 50 & 1 & 5,0 \% \\ \text { Entre } 51 \text { e } 70 & 9 & 45,0 \% \\ \text { Entre } 71 \text { e } 100 & \end{array}$

Fonte: elaborado pelos autores.

No cenário nacional, tendo por base o ano de 2016, a totalidade dos cursos de Psicologia está organizada em universidades (40,2\%), centros universitários $(14,8 \%)$ e faculdades $(45,0 \%)$. Comparando-se com a realidade dos cursos que foram objeto desta investigação, observa-se que, nos municípios menores, o percentual de cursos ofertados em universidades eleva-se significativamente (70,0\%) em detrimento dos cursos ofertados em faculdades (15,0\%), que, inclusive, igualam-se aos cursos ofertados em centros universitários (15,0\%). Considerando a missão das universidades, entende-se que tal fato pode contribuir para viabilizar formações ancoradas não apenas em ações de ensino, mas integradas às atividades de pesquisa e extensão, possibilitando, talvez, maior aproximação dos processos formativos dos alunos em relação às demandas sociais e à realidade de diferentes segmentos da sociedade.

Nesse sentido, destaca-se a importância das ações extensionistas, aliadas ao ensino e a pesquisa, enquanto um potente dispositivo de aproximação da formação em Psicologia com o campo das políticas públicas e movimentos sociais. $\mathrm{O}$ fortalecimento da relação ensino-serviço-comunidade abre diversas possibilidades formativas em que a construção do conhecimento e manejo prático se dá no serviço e para o serviço, podendo, assim, resultar na problematização dos mecanismos de natureza tecnicista e especialista, típico da racionalidade instrumental, que marca historicamente os saberes e fazeres psicológicos (Dimenstein, \& Macedo, 2012). Além disso, o fato de os cursos de Psicologia investigados estarem, em sua maioria, vinculados a universidades e centros universitários, possibilita maior oportunidade de articulação com graduações de diversas áreas do conhecimento (Saúde, Educação, Ciências Agrárias, etc.), inclusive daquelas que contam com maior inserção e acúmulo de experiências 
em pesquisas e intervenções direcionadas para os contextos rurais.

Outro aspecto a ser ressaltado no perfil dos 20 cursos analisados é a menor diferença entre o número de IES públicas $(40,0 \%)$ e privadas $(60,0 \%)$ existentes em regiões interioranas do país, se comparado à totalidade de cursos no cenário nacional (12,8\% e 84,3\%, respectivamente). A maior presença das IES públicas entre os cursos estudados deve-se notadamente ao Reuni, responsável por impulsionar o processo de interiorização do ensino superior, apesar de as IES privadas também terem acompanhado esse reposicionamento, considerando o nicho de mercado que se abriu para esse setor, sem dúvida, impulsionado pelos programas Fies e Prouni, já mencionados.

Tabela 2 -Localização dos cursos

\begin{tabular}{|c|c|c|c|c|c|}
\hline \multirow[t]{2}{*}{ Localização } & \multirow[t]{2}{*}{$\mathbf{N}$} & \multirow[t]{2}{*}{$\%$} & \multicolumn{3}{|c|}{ Porte populacional } \\
\hline & & & Médio & Médio-pequeno & Pequeno \\
\hline \multicolumn{6}{|l|}{ Região Sul } \\
\hline Rio Grande do Sul & 5 & $25,0 \%$ & 1 & 2 & 2 \\
\hline Santa Catarina & 1 & $5,0 \%$ & - & 1 & - \\
\hline \multicolumn{6}{|l|}{ Região Sudeste } \\
\hline São Paulo & 3 & $15,0 \%$ & 2 & 1 & - \\
\hline Minas Gerais & 1 & $5,0 \%$ & - & 1 & - \\
\hline Rio de Janeiro & 1 & $5,0 \%$ & - & - & 1 \\
\hline \multicolumn{6}{|l|}{ Região Nordeste } \\
\hline Ceará & 2 & $10,0 \%$ & 1 & 1 & - \\
\hline Alagoas & 1 & $5,0 \%$ & - & 1 & - \\
\hline Rio Grande do Norte & 2 & $10,0 \%$ & - & - & 2 \\
\hline Piauí & 1 & $5,0 \%$ & 1 & - & - \\
\hline \multicolumn{6}{|l|}{ Região Centro-Oeste } \\
\hline Mato Grosso do Sul & 1 & $5,0 \%$ & 1 & - & - \\
\hline Goiás & 1 & $5,0 \%$ & - & 1 & - \\
\hline \multicolumn{6}{|l|}{ Região Norte } \\
\hline Rondônia & 1 & $5,0 \%$ & - & 1 & - \\
\hline Total & 20 & $100 \%$ & 6 & 9 & 5 \\
\hline
\end{tabular}

Fonte: elaborado pelos autores

Os PPC analisados indicam que tais cursos estão localizados nas cinco regiões brasileiras. A maioria está na região Nordeste $(n=6)$ e Sul $(n=6)$, seguida do Sudeste $(n=5)$, Centro-Oeste $(n=2)$ e Norte $(n=1)$. Os cursos estão distribuídos 
em, pelo menos, 12 Estados, o que indica um dos efeitos das ações e programas acima mencionados de uma melhor distribuição da oferta de cursos de graduação nas regiōes brasileiras, deslocando do eixo principal Sul-Sudeste.

Além disso, nessas regiōes, 30\% dos cursos estão em municípios de médio porte; $45 \%$ em municípios de médio-pequeno porte; e $25 \%$ em localidades de pequeno porte. Se, por um lado, percebe-se um cenário que sinaliza para um quadro de interiorização da formação, por outro, evidencia-se uma tendência dos cursos em se instalarem em municípios de médio-pequeno e médio porte populacional. Tal fenômeno pode estar relacionado ao crescimento do perfil das cidades médias nas regiōes metropolitanas ou de desenvolvimento regional, em razão do "papel indutor da desconcentração industrial e do setor de serviços ou da expansão da fronteira agrícola, além das deseconomias de aglomeração dos grandes centros urbanos" (Stamm, Staduto, Lima, \& Wadi, 2013, p. 257).

Percebe-se também, por outra perspectiva, maior tendência à abertura de cursos em localidades que apresentam maior população urbana se comparada à rural, conforme critérios do Instituto Brasileiro de Geografia e Estatística (IBGE). Mas há exceções, como é o Município de Icó-CE, que conta com 53\% da população residindo na zona rural. Ademais, quando consideramos a crítica de alguns autores, a exemplo de Veiga (2001), sobre o entendimento de que o urbano equivale à área do distrito sede do Município, independentemente de suas características, critério adotado pelo IBGE, percebe-se que o rural não pode ser identificado apenas por aquilo que está fora do perímetro urbano dos municípios, muito menos pelas atividades exclusivamente agropecuárias. Assim, o autor propõe uma nova tipologia para urbano-rural, utilizando a densidade demográfica e o tamanho populacional, considerando como rurais os municípios com população menor que 50 mil habitantes ou com densidade demográfica menor que 80 hab. $/ \mathrm{km}^{2}$.

O critério adotado por Veiga $(2001 ; 2006)$, com base no parâmetro da densidade demográfica proposto pela Organização de Cooperação e de Desenvolvimento Econômico (OCDE), evidencia um país formado por $80 \%$ dos municípios com características rurais, onde residem aproximadamente $30 \%$ da população. São localidades marcadas pela necessidade de uma aproximação cada vez maior das relaçóes campo-cidade, consequentemente por políticas públicas "que estimulem a formulação descentralizada de projetos capazes de valorizar as características locais e/ou regionais" de cada território em desenvolvimento (Marcuzzo, \& Ramos, 2004, p. 2).

Considerar o processo de expansão e interiorização da formação em Psicologia pelo prisma de um Brasil mais "rural" do que imaginamos, a partir da perspectiva 
de Veiga $(2001 ; 2006)$, sugere que olhemos com maior atenção para a abertura de cursos em localidades de pequeno porte, como é o caso dos municípios de Pau dos Ferros-RN, Vassouras-RJ, Santiago-RS e Frederico Westphalen-RS, pois contam com população menor que 50 mil habitantes. Ou que olhemos para os municípios de médio-pequeno porte, a exemplo de Cacoal-RO, Icó-CE, JataíGO e São João del-Rei-MG, que, apesar de contarem com população entre 50 a 100 mil habitantes, têm densidade demográfica menor que 80 hab. $/ \mathrm{km}^{2}$. Portanto são localidades que, em alguma medida, comportam muita proximidade com a dinâmica territorial e os modos de vida e de trabalho característicos daquilo que os estudos rurais no Brasil têm denominado do continuum rural-urbano.

A ideia de continuum ajuda-nos a entender a ideia de rural não como oposto ao urbano, mas caracterizado por um gradiente de variações espaciais, de maneira que se vai de uma situação (rural) a outra (urbano), constituindo relaçôes de contato e gradação entre ambas, espécie de continuidade (aproximação e integração) entre os dois espaços, porém resguardadas as particularidades que os definem (Jacinto, Mendes, \& Perehouskei, 2012). Nesse aspecto, falar de rural na atualidade é entendê-lo como espaço singular permeado por uma multiplicidade de formas e pela própria diversidade das relaçôes dialéticas estabelecidas com o mundo urbano e a sociedade mais ampla.

Essa diversificação de elementos é tanto material, pois conta com estabelecimentos agropecuários, indústrias e setor de serviços, constituindo, assim, uma pluriatividade de fazeres e possibilidades de trabalho e condições de vida em contextos rurais, quanto sociocultural, pois comporta diferentes representações sociais e campos de sentidos dos espaços rurais e urbanos, os quais têm repercussão direta sobre as identidades sociais e culturais, direitos e posiçôes sociais dos sujeitos que ali vivem (Wanderley, 2000).

Tais aspectos, nesse sentido, exigem dos cursos de Psicologia maior sensibilidade para que os componentes curriculares e demais experiências formativas que propóem possam apreender a complexidade e a heterogeneidade que marca os meios e os povos rurais no Brasil, pois certamente tal público poderá, em algum momento, acessar os serviços psicológicos ofertados nesses municípios ou nas localidades próximas.

\subsection{CARACTERIZAÇÃO GERAL DOS PPC}

De acordo com Seixas et al. (2013), o "Projeto Pedagógico de Curso é um documento normativo dos cursos de graduação que apresenta características de projeto com informações acerca da concepção e da estrutura do curso e 
seus elementos reguladores internos" (p. 114). Nesse aspecto, trata-se de um instrumento de orientação e operacionalização do curso, em que constam as linhas gerais da proposta (histórico, caracterização e justificativa de criação ou reformulação do projeto pedagógico, além dos objetivos, perfil do egresso e competências e habilidades a que se pretende chegar); a organização do curso, com estrutura e conteúdo curricular, ementário, bibliografias, carga horária; além das estratégias de ensino e sistema de avaliação, infraestrutura e recursos humanos para o funcionamento.

Desde 2004, os currículos de Psicologia não são mais orientados pelo currículo mínimo instituído em 1962, mas pelas Diretrizes Curriculares Nacionais (DCN), que constituem um conjunto de orientaçōes, princípios, fundamentos e procedimentos para o planejamento, organização, implementação e avaliação dos cursos de graduação em Psicologia. O objetivo central dessa primeira mudança, após anos de intenso debate, foi priorizar uma formação ampla, respeitando a multiplicidade de concepçôes teóricas e metodológicas que conforma a ciência e a profissão em Psicologia.

O currículo passou ser organizado em núcleo comum e por estrutura de ênfases. O núcleo comum, constituído do início ao fim do curso, foi proposto para articular conhecimentos, competências e habilidades gerais, com base em eixos estruturantes que garantissem o contato do acadêmico com a diversidade da Psicologia, além de garantir uma formação generalista. São eles:

a) fundamentos epistemológicos e históricos;

b) fundamentos teórico-metodológicos;

c) procedimentos para investigação científica e prática profissional;

d) fenômenos e processos psicológicos;

e) interfaces com campos afins do conhecimento;

f) práticas profissionais.

Já a estrutura de ênfases, prevista na organização do currículo, trata-se de um momento de aprofundamento e concentração de estudos e estágios em algum domínio da Psicologia, em que são operacionalizados um subconjunto de competências e habilidades mais específicos e o diálogo com as demandas local e potencial em que os cursos estão situados (Resolução no 8/2004; Resolução no 5/2011). 
Todos os PPC investigados estão organizados em conformidade com as DCN de 2004 (Resolução no 8/2004), sendo 11 PPC estruturados como cursos novos e 9 como propostas de mudança ou reforma curricular para adequarem-se às diretrizes em Psicologia. Os motivos justificados para a reforma curricular nesses cursos foram a necessidade de inserir novas disciplinas e alterar ementas, além de renovar referências bibliográficas e mudanças nos estágios básicos e específicos. Ressalta-se que, dos 20 cursos investigados, somente 12 estão de acordo com as DCN de 2011, no sentido de considerarem a formação de professores em Psicologia (Resolução no 5/2011).

Bernardes (2012) chama a atenção para pensar o currículo não apenas como dispositivo de (re)produção de saberes, práticas, racionalidades e manejo técnico-profissional, pois impóe sentidos e valores, além de produzir sujeitos. Para o autor, o currículo não pode ser reduzido a um rol de disciplinas, inclusive desconectadas dos objetivos do curso, do perfil do egresso e das concepçôes e visôes de mundo e de sociedade presentes na proposta. O desafio é justamente tornar o trabalho de reforma ou de construção de um novo PPC como uma ação coletiva, com a participação de diversos atores, para que se tenha um amplo debate e clareza do tipo de mudança ou transformação que se quer alcançar.

Nesse aspecto, Vasconcelos (2006) indica que o processo de elaboração de um PPC implica em diversos fatores que podem enriquecer o debate e atender à maioria das necessidades postas, ou que podem ainda, inclusive, comprometêlo, a exemplo: do comodismo de alguns atores envolvidos que não desejam mudanças; ou ao imediatismo de outros, pouco afeitos a discussões; ou ainda ao perfeccionismo daqueles que intencionam aproximar-se de um currículo ideal. É nesse sentido que Bernardes (2012) retoma a ideia sobre a importância de ter claros alguns posicionamentos dos atores envolvidos nesse debate: "Qual o nível de reforma que se quer atingir?", "Qual o grau de compromisso assumido pelos atores envolvidos?", "Que perfil formativo será produzido?", "Que objetivos querem atingir?", "Que vozes constituem o curso?”, "Qual a vocação do curso?" (p. 220).

Entre os currículos analisados, os PPC que apresentaram proposta de criação de cursos novos, a participação ficou restrita basicamente aos docentes, sem qualquer menção quanto à participação de setores da sociedade em geral, inclusive da própria categoria profissional dos psicólogos e suas entidades de classe. Os PPC que trataram sobre mudança curricular, somente um, conforme o documento que o regulamenta, de Palmeira dos Índios-AL, em uma IES pública, contou com a participação da comunidade acadêmica e dos técnicos da instituição em sua reformulação. Dado que, no geral, reforça a opinião de Bernardes (2012), ao 
referir sobre a "baixa participação da comunidade acadêmica nos processos de reformas curriculares" (p. 219).

$\mathrm{O}$ argumento apresentado nas justificativas desses 20 cursos para que fossem autorizados era basicamente: "responder a problemas e demandas sociais" ( $\mathrm{n}=17)$, "demandas de mercado" ( $\mathrm{n}=10)$, "para promoção de saúde/qualidade de vida" (n=6) e "realizar ações de pesquisa" $(n=1)$. O destaque de que os cursos estariam voltados para os "problemas e demandas sociais" nas justificativas propostas reflete o alinhamento discursivo entre os documentos e o texto das DCN, e o debate sobre o compromisso social da profissão (Seixas, 2014). Porém os currículos não aprofundam, de forma pormenorizada e específica, quais seriam os problemas e demandas de cada localidade ou região em que os cursos estão inseridos, bem como possíveis contribuições da Psicologia como ciência e profissão para o desenvolvimento de cada município-sede e região em que o curso está situado.

Quanto ao profissional que se pretende formar, os PPC destacam como perfil um profissional comprometido social e eticamente $(n=12)$, de base generalista $(n=8)$ e pluralista $(n=5)$, com criticidade $(n=9)$ e autonomia $(n=6)$, voltado para a promoção de saúde/qualidade de vida da população $(n=9)$ e atuação multiprofissional e interdisciplinar $(\mathrm{n}=6)$, além da formação em pesquisa e aprimoramento acadêmico-científico $(\mathrm{n}=8)$, revelando o mesmo alinhamento discursivo entre os documentos e o texto das DCN. Outro aspecto que foi encontrado, apesar de figurar com menor frequência, diz respeito à busca por perfis profissionais que estejam preparados para as demandas locais $(n=5)$ e que consigam atender às demandas da região $(n=4)$, denotando a importância de pensar o contexto no qual o curso e a profissão estão inseridos. Nas duas situações, trata-se de cursos basicamente localizados em municípios de médiopequeno e pequeno porte populacional, a exemplo de Cacoal-RO, Icó-CE, Sobral-CE, Jataí-GO, Dourados-MS e Vassouras-RJ, sendo a maioria de IES privadas. Entretanto as características das localidades desses cursos não são especificadas nos documentos que os regulamentam, no sentido de fortalecer o diálogo com os componentes de cada currículo no tocante a disciplinas, estágios e ênfases dos cursos, para formar profissionais mais implicados com a realidade desses municípios.

\section{3. ÊNFASES CURRICULARES}

As ênfases curriculares, previstas nas DCN, surgiram com o entendimento de que a formação de psicólogos precisava oportunizar a concentração de estudos e atuação profissional, focando em competências e habilidades mais específicas, 
sem, entretanto, estarem estruturadas na matriz curricular como "momentos estanques do processo de formação" (Cury, 2012, p. 71). Nesse aspecto, cada curso pode oferecer o número de ênfases que o perfil profissional pretendido comporta, claro, respeitando o mínimo de duas, conforme estabelece as DCN (Resolução no 8/2004; Resolução no 5/2011).

Tabela 3 - Quantidade de ênfases curriculares ofertadas pelos cursos

\begin{tabular}{lcc}
\hline \multicolumn{1}{c}{ Quantidade de ênfases curriculares } & N & $\%$ \\
\hline Duas ênfases & 12 & $60,0 \%$ \\
Três ênfases & 4 & $20,0 \%$ \\
Quatro ênfases & 3 & $15,0 \%$ \\
Cinco ênfases & 1 & $5,0 \%$ \\
\hline Total & $\mathbf{2 0}$ & $\mathbf{1 0 0} \%$ \\
\hline
\end{tabular}

Fonte: elaborado pelos autores.

Os cursos estudados apresentam, em sua maioria $(\mathrm{n}=12)$, a oferta mínima de duas ênfases $(60 \%)$, como é sugerido pelas DCN. Os demais $(\mathrm{n}=8)$ apresentam de 3 a 5 ênfases, possibilitando maior variedade de áreas/campos da Psicologia em seus processos formativos. Ademais, pelo menos 16 cursos (80\%) apresentaram a escolha da ênfase de forma "padrão", ou seja, acompanhado pelo imperativo da escolha, por parte do aluno, de uma das ênfases ofertadas. Somente dois cursos permitem os alunos escolherem cursar mais de uma ênfase (10\%) ou foram organizados de modo que as ênfases não estejam dissociadas uma da outra (10\%). Não tomar as ênfases como excludente uma da outra e não as reduzir aos campos de estágio amplia e oportuniza maior número de experiências formativas, aproximando a formação do caráter generalista previsto nas DCN.

A área mais recorrente das ênfases ofertadas faz relação com "Psicologia e processos clínicos", seguida de "Psicologia e processos de prevenção e promoção da saúde" e "Psicologia, processos psicossociais e contextos comunitários e institucionais". As áreas "Psicologia e processos educativos" e "Psicologia e processos de gestão e trabalho", apesar de menor peso em relação às anteriores, mantêm boa presença entre os cursos investigados. 
Tabela 4 - Áreas abordadas pelas ênfases ofertadas nos cursos investigados

\begin{tabular}{lc}
\hline \multicolumn{1}{c}{ Áreas } & N \\
\hline Psicologia e processos clínicos & 18 \\
Psicologia e processos de prevenção e promoção da saúde & 12 \\
Psicologia e processos psicossociais e contextos comunitários e institucionais & 11 \\
Psicologia e processos educativos & 9 \\
Psicologia e processos de gestão e trabalho & 9 \\
Psicologia e processos de investigação científica & 1 \\
Psicologia e processos de avaliação e diagnóstico & 1 \\
Psicologia do desenvolvimento humano & 1 \\
\hline
\end{tabular}

Fonte: elaborado pelos autores.

O quadro geral das ênfases e suas descrições ao longo dos currículos reforça, em certa medida, as problematizações de Bernardes (2012), quando afirma que, mesmo depois de aprovadas as DCN em Psicologia, os cursos em funcionamento no Brasil ainda refletem o modelo anterior, ao concentrarem os estágios e disciplinas específicas nas chamadas áreas clássicas de atuação do psicólogo (clínica, escolar e do trabalho). Apesar da mudança da nomenclatura, que poderia representar uma nova concepção na formação, ao diferenciar áreas de conhecimento dos campos de atuação e objetos de estudo, ainda se vincula, na prática, as ênfases aos campos de estágio, resultando em reducionismos do tipo: a ênfase "processos clínicos" trata do fazer clínico em Psicologia e se realiza nos serviços de Psicologia aplicada/clínicas-escola; ênfase "Psicologia e processos educativos" trata da leitura e intervenção sobre os processos de ensino e aprendizagem e se realiza nas escolas; e a ênfase "Psicologia e processos de gestão e trabalho" se realiza em empresas. Tal aspecto, conforme comenta o autor, encontra força na racionalidade "aplicada" que ainda impera na formação dos psicólogos no País, pois não consegue apreender a complexidade de processos/ fenômenos que transitam ou são colocados em movimento num mesmo campo de atuação/intervenção.

Mesmo mantida a hegemonia da ênfase "Psicologia e processos clínicos" $(\mathrm{n}=18)$, pois impõe certa concepção clínica e de formação da identidade profissional como profissional liberal, outras ênfases foram inseridas pelas formações envolvendo conhecimentos e aprofundamento teórico-prático nas áreas da "saúde" e "contextos comunitários e institucionais", trazendo novas discussões e possibilidades para a Psicologia. Esse olhar direcionado à saúde e aos contextos comunitários e institucionais é reflexo do crescimento da profissão no âmbito das políticas públicas, considerando o aumento da oferta de trabalho 
nesses campos, notadamente nos municípios de menor porte populacional (Macedo, \& Dimenstein, 2011). Por outro lado, a maioria dos PPC investigados não apresentaram justificativas para criação das ênfases, e os poucos que o fizeram não estabeleceram qualquer relação com as demandas locais nas quais os cursos estão situados.

\subsection{MATRIZ CURRICULAR}

As matrizes curriculares dos cursos foram separadas de acordo com os eixos estruturantes estabelecidos pelas Diretrizes Curriculares em Psicologia.

Tabela 5 - Distribuição das disciplinas pelos eixos

\begin{tabular}{|c|c|c|c|c|c|c|c|c|c|c|c|c|}
\hline \multirow[t]{2}{*}{ Curso } & \multicolumn{2}{|c|}{$\begin{array}{l}\text { Fund. epist. e } \\
\text { históricos }\end{array}$} & \multicolumn{2}{|c|}{$\begin{array}{l}\text { Fund. teóricos e } \\
\text { metodológicos }\end{array}$} & \multicolumn{2}{|c|}{$\begin{array}{l}\text { Proced. para } \\
\text { investig. } \\
\text { científica } \\
\text { e prática } \\
\text { profissional }\end{array}$} & \multicolumn{2}{|c|}{$\begin{array}{l}\text { Fenômenos } \\
\text { e processos } \\
\text { psicológicos }\end{array}$} & \multicolumn{2}{|c|}{$\begin{array}{c}\text { Interfaces } \\
\text { com áreas } \\
\text { afins }\end{array}$} & \multicolumn{2}{|c|}{$\begin{array}{c}\text { Práticas } \\
\text { profissionais }\end{array}$} \\
\hline & $\mathrm{N}$ & $\%$ & $\mathrm{~N}$ & $\%$ & $\mathrm{~N}$ & $\%$ & $\mathrm{~N}$ & $\%$ & $\mathrm{~N}$ & $\%$ & $\mathrm{~N}$ & $\%$ \\
\hline Curso 1 & 3 & 4,6 & 19 & 29,6 & 2 & 3,1 & 16 & 25 & 18 & 28,1 & 6 & 9,6 \\
\hline Curso 2 & 2 & 3,3 & 19 & 31,2 & 5 & 8,2 & 23 & 37,7 & 7 & 11,4 & 5 & 8,2 \\
\hline Curso 3 & 1 & 2 & 10 & 19,2 & 7 & 13,5 & 18 & 34,6 & 6 & 11,5 & 10 & 19,2 \\
\hline Curso 4 & 6 & 11 & 11 & 20 & 8 & 14,5 & 19 & 34,5 & 8 & 14,5 & 3 & 5,5 \\
\hline Curso 5 & 3 & 5 & 21 & 35 & 5 & 8,3 & 19 & 31,7 & 6 & 10 & 6 & 10 \\
\hline Curso 6 & 2 & 3,3 & 18 & 29,5 & 5 & 8,1 & 17 & 27,9 & 11 & 18 & 8 & 13,2 \\
\hline Curso 7 & 6 & 9,1 & 7 & 10,6 & 11 & 16,7 & 25 & 37,8 & 6 & 16,7 & 11 & 9,1 \\
\hline Curso 8 & 3 & 4,3 & 28 & 38,9 & 6 & 8,3 & 21 & 29,1 & 10 & 13,9 & 4 & 5,5 \\
\hline Curso 9 & 7 & 13,2 & 8 & 15,1 & 2 & 3,8 & 13 & 24,5 & 7 & 13,2 & 16 & 30,2 \\
\hline Curso 10 & 2 & 2,8 & 23 & 32,8 & 4 & 5,7 & 20 & 28,5 & 11 & 15,7 & 10 & 14,5 \\
\hline Curso 11 & 2 & 3,7 & 13 & 23,7 & 8 & 14,5 & 12 & 21,8 & 12 & 21,8 & 8 & 14,5 \\
\hline Curso 12 & 3 & 5 & 14 & 23 & 4 & 6,5 & 20 & 32,7 & 11 & 18 & 9 & 14,8 \\
\hline Curso 13 & 3 & 3,9 & 24 & 31,3 & 7 & 9,1 & 25 & 32,4 & 11 & 14,2 & 7 & 9,1 \\
\hline Curso 14 & 2 & 3,6 & 21 & 37,5 & 5 & 9 & 15 & 26,8 & 9 & 16,1 & 4 & 7 \\
\hline Curso 15 & 2 & 2,6 & 31 & 40,2 & 6 & 7,8 & 19 & 24,7 & 8 & 10,4 & 11 & 14,3 \\
\hline Curso 16 & 2 & 2,6 & 31 & 40,2 & 6 & 7,8 & 19 & 24,7 & 8 & 10,4 & 11 & 14,3 \\
\hline Curso 17 & 2 & 2,6 & 31 & 40,2 & 6 & 7,8 & 19 & 24,7 & 8 & 10,4 & 11 & 14,3 \\
\hline Curso 18 & 2 & 2,6 & 31 & 40,2 & 6 & 7,8 & 19 & 24,7 & 8 & 10,4 & 11 & 14,3 \\
\hline Curso 19 & 4 & 6,3 & 17 & 26,6 & 5 & 7,9 & 21 & 32,8 & 11 & 17,2 & 6 & 9,2 \\
\hline Curso 20 & 2 & 4,3 & 23 & 32,4 & 5 & 7,1 & 27 & 38,0 & 7 & 9,8 & 6 & 8,4 \\
\hline Total & 59 & - & 400 & - & 113 & - & 387 & - & 183 & - & 163 & - \\
\hline
\end{tabular}

Fonte: elaborado pelos autores. 
O eixo que mais se destacou com concentração de disciplinas foi "Fundamentos teórico-metodológicos", que trata sobre as teorias psicológicas e apresenta os objetos e estratégias de intervenção em Psicologia (Seixas, 2014). Para o autor, isso sugere currículos com maior enfoque em conteúdos e técnicas, a exemplo de disciplinas como as escolas tradicionais de Psicologia (Psicodinâmicas, Fenomenológicas e Comportamentais), além de "Métodos e Técnicas de Avaliação Psicológica", "Teorias e Práticas Psicoterápicas", "Orientação e Aconselhamento Psicológico", "Teorias da Subjetividade", "Teorias da Personalidade" e "Teoria e Método de intervenção". Tal concentração acaba distanciando os currículos daquilo que propunha as DCN, no sentido de superar as exigências meramente conteudistas, organizadas de forma compartimentada.

O segundo eixo mais frequente foi "Fenômenos e processos psicológicos", com discussóes a respeito de objetos específicos na Psicologia. Os fenômenos abordados pelas disciplinas desse eixo foram: os processos básicos e superiores, a subjetividade, o comportamento, a aprendizagem e os processos psicossociais baseados nos contextos comunitários e institucionais, entre outros.

Assim como no estudo de Seixas (2014), poucas disciplinas abordaram fenômenos que se relacionam com as demandas sociais e as políticas sociais brasileiras. O destaque foi para "Psicologia Comunitária" que, mesmo não tendo o caráter obrigatório em todos os currículos pesquisados, era uma das poucas que figurava no currículo com discussōes acerca do contexto local e sua cultura, cidadania, direitos humanos, políticas públicas voltadas para a comunidade e saúde mental. Ademais, alguns cursos apresentaram disciplinas isoladas, de caráter eletivo, com debates sobre movimentos sociais (embora mais relacionados aos contextos urbanos), diversidade étnico-racial, identidades sociais, Psicologia política, políticas públicas, cidadania, relações locais e globais, propondo alguma discussão acerca da localidade onde o curso funcionava.

\subsection{PRÁTICAS}

De acordo com Cury e Ferreira Neto (2014), o Parecer no 403, de 1962, do Conselho Federal de Educação, que instituiu o Currículo Mínimo em Psicologia, definiu o estágio como quesito essencial e obrigatório para a obtenção do grau de psicólogo, com no mínimo 500 horas de atividades práticas, de caráter supervisionado, ocorrendo no último ano do curso.

Do currículo mínimo até a aprovação das DCN em Psicologia, em 2004, muitos foram os debates sobre a necessidade de qualificação e reorganização 
dos estágios para a formação de psicólogos no Brasil. De forma sintética, os autores recuperaram, em suas análises, os principais avanços dos documentos produzidos nesse período: aumento da carga horária dos estágios, realocar os estágios e distribuí-los ao longo de todo o currículo, de maneira a não os restringir aos últimos períodos dos cursos, e ampliar a diversidade de oferta de cenários de práticas, visando superar a centralidade da formação hegemônica de modelo liberal na profissão (Cury, \& Ferreira Neto, 2014).

Em que pesem as controversas quanto à aprovação das DCN em Psicologia em 2004, os estágios supervisionados ficaram caracterizados como "conjuntos de atividades de formação, programados e diretamente supervisionados por membros do corpo docente da instituição formadora e procuram assegurar a consolidação e articulação das competências estabelecidas" (Resolução no 8/2004, p. 17). Foram estruturados em dois níveis, básico e específico, e com o objetivo de desenvolver práticas integrativas das competências e habilidades previstas tanto no núcleo comum dos currículos quanto de cada ênfase proposta pelo projeto de curso. A proposta era romper com a ideia do currículo organizado em disciplinas teóricas de um lado, conformando quase a totalidade da matriz curricular dos cursos e, do outro, os estágios como o momento específico de prática profissional. Dessa forma, objetivava-se aproximar gradativamente os estudantes dos diferentes cenários de prática profissional, por meio de atividades integradas que diminuiriam a distância entre teoria e prática (Santos, \& Nóbrega, 2017). Ademais, ficou estabelecido a carga horária dos estágios básicos e específico de, no mínimo, $15 \%$ do total de horas do curso.

Para caracterizar os estágios básicos e específicos dos 20 cursos investigados, verificou-se a carga horária e a quantidade ofertada. A maioria dos estágios básicos dos cursos estudados apresenta carga horária total entre $80 \mathrm{~h}$ e $160 \mathrm{~h}$, com quantidade que varia entre 2 e 4 estágios distribuídos ao longo do curso. Alguns cursos alargaram a carga horária dos estágios básicos, chegando, em alguns casos, a até $585 \mathrm{~h}$ e oferecendo 7 estágios básicos. Em relação ao estágio específico, a carga horária de maior frequência entre os cursos foi entre $601 \mathrm{~h}$ e 840 h, apresentando entre 2 e 4 estágios $(n=16)$. 
Tabela 6 -Características dos estágios básicos e específicos em relação à carga horária e quantidade de estágios

\begin{tabular}{lcc}
\hline Carga horária/Quantidade de estágios & N & $\%$ \\
\hline Estágio básico & 11 & $55,0 \%$ \\
Entre 80h e 160h & 3 & $15,0 \%$ \\
Entre 161h e 240h & 6 & $30,0 \%$ \\
Entre 241h e 585h & & \\
Estágio específico & 7 & $35,0 \%$ \\
Entre 300h e 450h & 5 & $25,0 \%$ \\
Entre 451h e 600h & 8 & $40,0 \%$ \\
Entre 601h e 840h & & \\
\hline Estágio básico & 17 & $85,0 \%$ \\
Entre 2 e 4 & 3 & $15,0 \%$ \\
Entre 5 e 7 & & \\
Estágio específico & 16 & $80,0 \%$ \\
Entre 2 e 4 & 4 & $20,0 \%$ \\
Entre 5 e 8 & & \\
\hline
\end{tabular}

Fonte: elaborado pelos autores.

Dos 20 PPC analisados, 85,0\% $(\mathrm{n}=17)$ especificaram mais detidamente os objetivos tanto do estágio básico quanto do estágio específico. No caso do estágio básico, 57,9\% ( $\mathrm{n}=12)$ dos cursos sinalizaram como objetivo a integração de conhecimentos, habilidades e rotinas técnicas apresentados no núcleo comum; $26,3 \%(n=6)$ trouxeram como objetivo a oportunidade de contato com os campos de atuação da profissão; e 5,2\% ( $n=2)$ relataram que o estágio básico serviu para a consolidação da teoria e prática.

Em relação ao estágio específico, 14 cursos $(70,0 \%)$ mostraram como objetivo a integração com a ênfase/área escolhida, e os outros 3 cursos $(15,8 \%)$ sinalizaram como objetivo a possibilidade de ter contato com o campo de atuação e mercado de trabalho da profissão. Nos documentos pesquisados, eleva-se a importância dos estágios específicos, em virtude de estes se apresentarem mais organizados e definidos em relação aos estágios básicos, considerados como mais amplos e sujeitos a alteraçôes de acordo com a proposta de cada contexto.

Outro aspecto procurado durante as análises foi a relação dos estágios básicos e específicos, mas essa informação se apresentou escassa nos documentos, visto que, dos 19 cursos, nenhum apresentou essa informação. Ou seja, não há uma linha articuladora entre estágios básicos e específicos, pois são apresentados nos documentos de maneira desvinculada, como se ambos não se integrassem ou 
se complementassem. $\mathrm{Na}$ tabela 7 , podemos acompanhar os locais de estágio citados nos documentos como campos possíveis de cenários de práticas a serem ofertados aos estudantes desses cursos.

Tabela 7 - Locais de estágio propostos pelos cursos

\begin{tabular}{lcc}
\hline Locais de estágio & N & \% (do total) \\
\hline Serviço Psicologia Aplicada/Clínica-Escola de Psicologia & 19 & 95,0 \\
Escolas & 11 & 55,0 \\
Comunidades/Contextos rurais & 8 & 40,0 \\
Empresas/Organizações & 6 & 30,0 \\
Dispositivos de saúde & 5 & 25,0 \\
Hospitais & 3 & 15,0 \\
Instituições jurídicas & 1 & 5,0 \\
\hline
\end{tabular}

Fonte: elaborado pelos autores.

Destacam-se os Serviços de Psicologia Aplica/Clínica-Escola como espaço preferencial a ser usado como cenário de práticas. Apenas um curso não ofertou essa opção. É frequente as IES contarem com Serviços de Psicologia Aplica/ Clínica-Escola, já que as diretrizes curriculares indicam a instalação de um serviço de Psicologia para atender às necessidades de formação do psicólogo articulada ao perfil proposto pelo curso e às demandas da localidade onde está inserido. Em seguida, têm-se as Escolas/Instituições de Ensino como espaço de prática, sendo referidas em 55\% do total dos cursos investigados. Esse local complementa, junto com os Serviços de Psicologia Aplica/Clínica-Escola, a inserção dos estágios em áreas "tradicionais" da Psicologia, a depender de como as práticas formativas são realizadas nesses espaços.

O dado que chamou atenção, ainda que presente em menos da metade dos cursos investigados, foi a oferta de estágios em comunidades e contextos rurais $(\mathrm{n}=8)$. O destaque é para cursos localizados na Região Nordeste, em municípios de médio e médio-pequeno porte, e em IES públicas. No geral, esses cursos estão localizados nos seguintes municípios: Parnaíba-PI, Icó-CE, Sobral-CE, Santa Cruz-RN, Dourados-MS, São João del-Rei-MG, Vassouras-RJ e Marília-SP. Esse aspecto responde, em certa medida, ao fato de que cada vez mais os psicólogos têm atuado em meios rurais, mas, por outro lado, sem experiência teórico-crítica e prática anterior nesse campo. Tal realidade se constitui como um desafio que passa, antes de tudo, pela limitada e deficiente formação em Psicologia voltada para as questôes que envolvem os contextos rurais (Leite et. al, 2013). Também foi referido por alguns cursos certos dispositivos de saúde $(\mathrm{n}=5)$, a exemplo do Centro de Atenção Psicossocial (CAPS), Unidade Básica de Saúde (UBS), como 
cenário de práticas para os estágios específicos, o que responde, de alguma forma, à necessidade de formar psicólogos para atuarem nos equipamentos das políticas sociais, considerando o fortalecimento da inserção profissional nesse campo, nos últimos anos (Dimenstein, \& Macedo, 2012).

No geral, percebe-se que os cursos investigados, com algumas exceções, apresentam, em seus documentos, propostas de estágios de forma ampla e sem conexão com a rede de serviços e, ou, necessidades da população e características locais. Destaca-se a preferência pela oferta de estágios nas áreas tradicionais da profissão. Somente um único curso, localizado no Município de Icó/CE, de caráter privado, sinalizou, nos documentos que o regulamentam, a oferta de atividades de extensão voltadas para contribuir com o desenvolvimento social, quer seja em áreas urbanas ou rurais.

\section{CONSIDERAÇÕES FINAIS}

Apesar de os dados oficiais indicarem o nosso país como urbano, pois somente $15,5 \%$ da população vive em áreas rurais, $70,4 \%$ dos municípios têm população menor que 20 mil habitantes, e 18,7\%, entre 20 a 50 mil habitantes (Instituto Brasileiro de Geografia e Estatística, 2010), autores como Veiga (2001; 2006) questionam o critério empregado pelo IBGE. Segundo o autor, o Brasil é o único país no mundo que toma o urbano relacionando à sede dos municípios, não importando suas características estruturais ou funcionais. Assim, propõe como critério, já aludido anteriormente, os municípios essencialmente rurais (população menor que 50 mil habitantes), os relativamente rurais (mais de 50 a 100 mil habitantes, ou cuja densidade supere os $80 \mathrm{hab} / \mathrm{km}^{2}$ ) e aqueles ditos essencialmente urbanos (municípios com mais de 100 mil habitantes).

Sob esse parâmetro, teríamos, pelo menos, 4.485 municípios brasileiros que seriam rurais. Por conseguinte, os cursos de Psicologia localizados exatamente nesses municípios estariam mais próximos, de alguma maneira, das características próprias e da heterogeneidade que marcam os contextos e os povos rurais no Brasil, em termos do seu ethos, níveis de organização social, política e comunitária, como também as relações de trabalho, formas de adoecimento, processos educativos, relações familiares, cultura, regras sociais, atitudes, valores, sociabilidades, etc. Mesmo assim, a Psicologia brasileira continua hegemonicamente alinhada por um modo de apreender a realidade e compreender os fenômenos que investiga pelo crivo da lógica urbana, inclusive com uma produção de conhecimento que tem margeado a realidade dos municípios menores ou mesmo dos povos e meios rurais (Albuquerque, 1996; Landini et al., 2015). 
A partir desta pesquisa, percebe-se a complexidade do cenário de formação que os psicólogos estão inseridos. Mesmo com as mudanças previstas pelas Diretrizes Curriculares em relação à formação em Psicologia, que se pretendem mais próximas à realidade na qual os cursos estão inseridos, os documentos pesquisados pouco dialogam com as particularidades locais e as necessidades da população de cada região em que o curso está localizado. De maneira geral, ainda encontramos os resquícios de uma formação amplamente criticada na produção de conhecimento nacional sobre o psicólogo brasileiro. Espera-se que, com este trabalho, abram-se caminhos para novas discussões e reflexões, no intuito de contribuir com uma formação voltada e pensada para uma realidade social mais ampla. 


\section{REFERÊNCIAS}

Albuquerque, F. J. B. (1996). Aspectos psicossociais do mundo agrário. Revista de Psicologia, 13-14(1-2), 69-75.

Bernardes, J. S. (2012). A formação em Psicologia após 50 anos do primeiro currículo nacional da Psicologia: alguns desafios atuais. Psicologia: Ciência e Profissão, 32 (n. esp.), 216-231.

Conselho Federal de Psicologia (2018). Ano da formação em Psicologia: revisão das diretrizes curriculares nacionais para os cursos de graduação em Psicologia. Brasília: CFP.

Conselho Nacional de Educação (2019). Parecer CNE/CES no 1071 que aprova a Revisão das Diretrizes Curriculares Nacionais (DCNs) dos Cursos de Graduação em Psicologia e estabelecimento de normas para o Projeto Pedagógico Complementar (PPC) para a Formação de Professores de Psicologia. Brasília: MEC, CNE, CES.

Cury, B. M., \& Ferreira Neto, J. L (2014). Do currículo mínimo às diretrizes curriculares: os estágios na formação do psicólogo. Psicologia em Revista, (20)3, 494-512.

Cury, D. G. (2012). A relação entre professor e aluno no ensino superior vista por meio da reprovação. (Dissertação de Mestrado). Universidade Federal de Uberlândia, Programa de Pós-graduação e Psicologia, Uberlândia.

Dimenstein, M., \& Macedo, J. P. (2012). Formação em Psicologia: requisitos para atuação na atenção primária e psicossocial. Psicologia, Ciência e Profissão, 32 (n. esp.), 232-245.

Instituto Brasileiro de Geografia e Estatística. (2010). Censo demográfico do Brasil de 2010. Rio de Janeiro: IBGE.

Jacinto, J. M., Mendes, C. M., \& Perehouskei, N. A. (2012). O rural e o urbano: contribuições para a compreensão da relação do espaço rural e do espaço urbano. Percurso, 4(2), 173-191.

Landini, F., Saforcada, E., Quintanar, C. S., Almaral, M. I., Wiesenfeld, E., Long, N., \& Méndez, A. O. (2015). Hacia una Psicología rural latinoamericana. Buenos Aires: Clacso.

Leite, J. F., Macedo, J. P. S., Dimenstein, M., \& Dantas, C (2013). A formação em 
Psicologia para a atuação em contextos rurais. In J. F. Leite, \& M. Dimenstein (Orgs.), Psicologia e contextos rurais. (pp. 27-55). Natal: EDUFRN.

Macedo, J. P., \& Dimenstein, M. (2011). Expansão e interiorização da Psicologia: reorganização dos saberes e poderes na atualidade. Psicologia: Ciência e Profissão, 31(2), 296-313.

Macedo, J. P., Lima, M. S. S., Dantas, C., \& Dimenstein, M. (2017). Transnacionalização do ensino superior: impactos nos processos formativos em Psicologia no Brasil. Psicologia, Ciência e Profissão, 37(4), 852-868.

Mancebo, D., Silva Júnior, J. R., \& Schugurensky, D. (2016). A educação superior no Brasil diante da mundialização do capital. Educação em Revista, 32(4), 205-225.

Marcuzzo, J. L., \& Ramos, M. P. (2004). A definição do rural e urbano e o desenvolvimento regional: uma avaliação de diferentes metodologias de classificação. In Anais, 2 Seminário Internacional sobre Desenvolvimento Regional, Santa Cruz do Sul. Santa Cruz do Sul: Programa de Pós-Graduação em Desenvolvimento Regional Mestrado e Doutorado, Unisc. Recuperado a partir de https://www.unisc.br/site/sidr/2004/urbano/01.pdf

Ministério da Educação. (1995). Instituto Nacional de Estudos e Pesquisas Educacionais Anísio Teixeira. Microdados do Censo da Educação Superior 1995: resumo técnico. Brasília: MEC, INEP.

Ministério da Educação. (2003). Instituto Nacional de Estudos e Pesquisas Educacionais Anísio Teixeira. Censo da Educação Superior 2003: notas estatísticas. Brasília: MEC, INEP.

Ministério da Educação. (2016). Instituto Nacional de Estudos e Pesquisas Educacionais Anísio Teixeira. Censo da Educação Superior 2016: notas estatísticas. Brasília: MEC, INEP.

Resolução no 5, de 15 de março de 2011. (2011, 15 março). Institui as Diretrizes Curriculares Nacionais para os cursos de graduação em Psicologia, estabelecendo normas para o projeto pedagógico complementar para a formação de professores de Psicologia. Brasília: Ministério da Educação, Conselho Nacional de Educação, Câmara de Educação Superior.

Resolução no 8, de 7 de maio de 2004. (2004, 7 maio). Institui as Diretrizes Curriculares Nacionais para os cursos de graduação em Psicologia. Brasília: Ministério da Educação, Conselho Nacional de Educação, Câmara de 


\section{Educação Superior.}

Rosas, P., Rosas, A., \& Xavier, I. B. (1988). Quantos e quem somos. In Conselho Federal de Psicologia, Quem é o psicólogo brasileiro?. (pp. 32-48). São Paulo: Edicon.

Santos, A. C., \& Nóbrega, D. O. (2017). Dores e delícias em ser estagiária: o estágio na formação em Psicologia. Psicologia, Ciência e Profissão, 37(2), 512528.

Seixas, P. S. (2014). A formação graduada em Psicologia no Brasil: reflexão sobre os principais dilemas em um contexto Pós-DCN. (Tese de Doutorado). Universidade Federal do Rio Grande do Norte, Programa de Pós-graduação e Psicologia, Natal.

Seixas, P. S., Coelho-Lima, F., Silva, S. G. \& Yamamoto, O. H. (2013). Projeto Pedagógico de Curso e formação do psicólogo: uma proposta de análise. Psicologia Escolar Educacional, 17(1), 113-122.

Stamm, C., Staduto, J. A. R, Lima, J. F., \& Wadi, Y. M. (2013). A população urbana e a difusão das cidades de porte médio no Brasil. Interações, 14(2), 251265.

Vasconcellos, C. S. (2006). Planejamento: projeto de ensino aprendizagem e projeto politico-pedagógico: elementos metodológicos para elaboração e realizaçāo. (5a ed.). São Paulo: Liberdade.

Veiga, J. E. (2001). O Brasil rural ainda não encontrou seu eixo de desenvolvimento. Estudos Avançados, 15(43), 101-119.

Veiga, J. E. (2006). Nascimento de outra ruralidade. Estudos Avançados, 20(57), 333-353.

Wanderley, M. N. B. (2000). A emergência de uma nova ruralidade nas sociedades modernas avançadas: o "rural" como espaço singular e ator coletivo. Estudos Sociedade e Agricultura, 15, 87-145 